\title{
26192 - EFFECT OF NALBUPHINE AND MIDAZOLAM ON HAEMODYNAMIC RESPONSE TO INTUBATION
}

\author{
Naila Asad MS Anaesthesiology, Khawar Ali, FCPS Anaesthesiology ; Abdul \\ Qayyum, Diplomat Iranian Board Of Anaesthesiology; Mazhar Iqbal; \\ Mayo Hospital Lahore -Pakistan, Lahore, PUNJAB, Pakistan
}

INTRODUCTION:

Laryngoscopy and tracheal intubation produce stress response in the form of tachycardia, hypertension and increased levels of catecholamines.1,2, As the control of blood pressure and heart rate is of utmost importance to prevent the detrimental effects; there is a need for a safe and effective drug to attenuate the cardiovascular response to laryngoscopy and intubation. Nalbuphine and midazolam are inexpensive and most commonly used in our community as a premedicant. Our aim was to compare the effects of nalbuphine and midazolam on haemodymanic responses to endotracheal intubation to help the selection of a better drug in this respect.

METHOD:

After approval from the hospital committee a study was carried out on ninety adult male patients of ASA I or II status, undergoing general surgery under standard general anaesthesia. After informed consent, three groups of 30 patients each were made by random allocation. On arrival in the theatre, E.C.G monitor, pulse oximeter and Noninvasive blood pressure monitor were applied. After 3 minutes of preoxygenation, all groups were induced with thiopentone $4 \mathrm{mg} / \mathrm{kg}$ and suxamathonium $1 \mathrm{mg} / \mathrm{kg}$. Group I was control in which $3 \mathrm{ml}$ of saline was given. Group II received nalbuphine $75 \mathrm{ug} / \mathrm{kg}$ and Group III received midazolam 30ug/kg before the induction agents. Following intubation, anaesthesia was maintained with $\mathrm{O} 2+\mathrm{N} 2 \mathrm{O}+$ halothane $(0.8 \%)$. Heart rate, systolic blood pressure, diastolic blood pressure and mean arterial pressure were recorded before induction, at laryngoscopy and intubation and after intubation every minute for three minutes. Concluding parameters were analysed statistically by ANOVA. $\mathrm{p}<0.05$ was taken as significant.

RESULTS:

Demographic data showed similarity in age and weight between groups. Baseline values did not differ significantly between groups. A decrease in HR ,SBP, DBP, MAP was seen in Group II and III but the decrease was more pronounced in Group II. $(\mathrm{p}<0.05)$ DISCUSSION:

The haemodynamic observations were noteworthy in our study. Significant attenuation of cardiovascular response to laryngoscopy and tracheal intubation was seen with nalbuphine and midazolam as compared to the control group. Analysis of haemodynamic response showed better suppression with nalbuphine than midazolam. The results of our study were consistent with previous study showing reduction in heart rate and systolic arterial pressure with nalbuphine as compared to other drugs.4

CONCLUSION:

Our study results suggest that nalbuphine when used as premedicant, in dose of $75 \mathrm{ug} / \mathrm{kg}$ is more effective than midazolam in blunting the stress response to laryngoscopy and intubation. We recommend its use in our settings before induction of anaesthesia. REFERENCES: 
1. J Anaesth Clin Pharmacol 2002;18:304-8.

2. Annals KEMC, Lahore, July-Dec 1996; 2:47-48.

3. Br J Anaesth 2001;86(1):90-3.

4. $\quad$ Middle East J Anaesthesiol 2004;17(6):1023-36.

Effect of Nalbuphine and Midazolam on the Haemodynamic Response to Intulbation.

\begin{tabular}{|c|c|c|c|c|c|}
\hline & $\begin{array}{l}\text { bofo! re Ladection } \\
\text { Measisd }\end{array}$ & $\begin{array}{l}\text { at Inrebation } \\
\text { meanusd }\end{array}$ & \multicolumn{3}{|c|}{$\begin{array}{l}\text { after Latubation } \\
\text { meanisd }\end{array}$} \\
\hline \multicolumn{6}{|l|}{ Grotp I } \\
\hline $\mathrm{HR}$ & $\$ 2=9.8$ & $104 \pm 8.9$ & $100 \pm 6.4$ & $94 \pm 6.9$ & $90 \pm 7.6$ \\
\hline SBP & $125 \div 16$ & $157 \pm 128$ & $140 \pm 10$ & $140 \div 10$ & $122+11$ \\
\hline DBP & $90 \times 9.3$ & $104 \pm 6.7$ & $97=5.3$ & $53 \pm 7.1$ & $83 \pm 7.1$ \\
\hline MAP & $95 \times 11.1$ & $122 * 8.6$ & $111+6.3$ & $97 \pm 8.1$ & 9607.9 \\
\hline \multicolumn{6}{|l|}{ Groty II } \\
\hline HR & $82 * 11.7$ & $89 * 10$ & $83 * 10.3$ & 81.9 .9 & $79+9.4$ \\
\hline SBP & $134=17.5$ & $140 \pm 10$ & $135 \pm 10.2$ & $134 \leq 9.8$ & $130 \pm 9,9$ \\
\hline DBP & $\$ 7 * 9.1$ & $90 * 10.2$ & $90 * 9.1$ & $85 \neq 9.3$ & $85+9.5$ \\
\hline MAP & $163 \pm 11.5$ & $106 \pm 11.8$ & $105 \pm 10.6$ & $101 \pm 99$ & $100=10$ \\
\hline \multicolumn{6}{|l|}{ Group III } \\
\hline HR & $92 \pm 16$ & $97=14.5$ & $93 \pm 11.3$ & $58 \pm 11$ & $37 \pm 11$ \\
\hline SBP & $127=13$ & $139 \pm 8.5$ & $135 \pm 9,4$ & $130 \pm 8$ & $128+4.4$ \\
\hline DBP & $84 * 7.1$ & $90 * 9.2$ & 8746.2 & $84 * 4.8$ & $82: 4.3$ \\
\hline MAP & $95=7.3$ & $105 * 10.1$ & $103 * 6.6$ & s9us.3 & $97+3.9$ \\
\hline
\end{tabular}

